\title{
Optimization of the Conceptual Model of Green-Ampt Using Artificial Neural Network Model (ANN) and WMS to Estimate Infiltration Rate of Soil (Case Study: Kakasharaf Watershed, Khorram Abad, Iran)
}

\author{
Ali Haghizadeh, Leila Soleimani, Hossein Zeinivand \\ Department of Watershed Management Engineering, Faculty of Agriculture, Lorestan University, \\ Khorramabad, Iran \\ Email: Alihaghi20@gmail.com, haghizadeh.a@lu.ac.ir
}

Received 16 January 2014; revised 15 February 2014; accepted 12 March 2014

Copyright (C) 2014 by authors and Scientific Research Publishing Inc.

This work is licensed under the Creative Commons Attribution International License (CC BY). http://creativecommons.org/licenses/by/4.0/

(c) (i) Open Access

\begin{abstract}
Determination of the infiltration rate in a watershed is not easy and in empirical and theoretical point of view, it is important to access average value of infiltration. Infiltration models has main role in managing water sources. Therefore different types of models with various degrees of complexity were developed to reach this aim. Most of the estimating methods of soil infiltration are expensive and time consuming and these methods estimate infiltration with hypothesis of zero slope. One of the conceptual and physical models for estimating soil infiltration is Green-Ampt model which is similar to Richard model. This model uses slope factor in estimating infiltration and this is the power point of Green-Ampt model. In this research the empirical model of GreenAmpt was optimized with integrating artificial neural network model (ANN) and a model of geographical information system WMS to estimate the infiltration in Kakasharaf watershed. Results of the comparison between the output of this method and real value of infiltration in region (through multiple cylinders) showed that this method can estimate the infiltration rate of Kakasharaf watershed with low error and acceptable accuracy (Nash-Sutcliff performance coefficient $\mathbf{0 . 8 2 1}$, square error 0.216 , correlation coefficient 0.905 and model error 0.024 ).
\end{abstract}

\section{Keywords}

Infiltration, Green-Ampt Empirical Model, WMS Model, Artificial Neural Network Model (ANN)

How to cite this paper: Haghizadeh, A., Soleimani, L. and Zeinivand, H. (2014) Optimization of the Conceptual Model of Green-Ampt Using Artificial Neural Network Model (ANN) and WMS to Estimate Infiltration Rate of Soil (Case Study: Kakasharaf Watershed, Khorram Abad, Iran). Journal of Water Resource and Protection, 6, 473-480. 


\section{Introduction}

One of the most important purposes in managing natural resources is conservation of the soil and water. Totally, there are three main factors in this purpose which are precipitation, infiltration and runoff. Increasing of soil infiltration and reducing runoff velocity and volume are the main aims for soil and water conservation. Infiltration is one of the important physical factors of soil which affects soil quality, vegetation feed, runoff rate and soil erosion. Factors such as soil texture, soil structure, and rate of organic matter, management and type of soil layers affect infiltration rate [1]. Infiltration of water into soil is as a primary process of water entering from soil surface into unsaturated region of soil. This process is as main parts of hydrological cycle and is defined as entering water from soil surface into soil. The quantification of soil infiltration is important issue in management of watershed. Infiltration models has main role in managing water sources. Therefore, different types of models with various degrees of complexity were developed to reach this aim [2]. Most of the estimating methods of soil infiltration are expensive and time consuming and with hypothesis of zero slope [3]. All of the infiltration equations can be divided into two groups of empirical and theoretical equations. Philip equation and Green-Ampt equation are the most important theoretical equations Horton and Kostiakovequations. Each of these equations has their benefits and limitations [4] [5]. The existence methods about determining the infiltration are divided into two groups. The first group is the theoretical methods or equations which are used to access approximate rate of infiltration. In second group it is possible to measure infiltration using based on flood and precipitation relation or using experimental analysis by penetrometer at small plots. Reference [6] in an article investigated the models of Philip and Green-Ampt using 35 multiple ring infiltration experiment in Masil Palangan watershed in Neyriz at the south of Iran. Results showed that the Green-Ampt model was the best model to estimate infiltration. References [7] [8] used the Green-Ampt model to convert pure rainfall at unstable condition to pure rainfall. Reference [9] compared the Philip, Green-Ampt and Horton models together for different types of soil and calculated the models parameters especially for Green-Ampt model. Results showed that the parameters of Green-Ampt model were in agreement with the results of numerical analysis. The reason of this finding is considering water stable status of model when the rainfall intensity was more than that of hydraulic conductivity. Reference [10] modeled the infiltration process in silt soil using corrected Green-Ampt and Hydrus-Id model. They simulated the infiltration using uncorrected Green-Ampt, corrected Green-Ampt and Hydrus-Id and then compared the results with observation values. Results showed that the corrected Green-Ampt model was in agreement with the real status. Reference [11] in a research entitled "investigation of the GIS-base model to optimize infiltration estimation models according to the slope and land use" investigated the effects of different slopes on Green-Ampt infiltration model. Results showed that among the different slope factors in Green-Ampt infiltration model the square of slope cosine was the most suitable factor in study area and can be used to calculate infiltration. In this research the empirical model of Green-Ampt was optimized with integrating artificial neural network model (ANN) and a model of geographical information system WMS to estimate the infiltration In Kakasharaf watershed.

\section{Materials and Methods}

\subsection{Study Area}

Kakasharaf watershed with an area of 10798.3 hectare is located in Lorestan province, the south east of Khorram Abad city. The geographical position is from $48^{\circ} 39^{\prime} 8^{\prime \prime}$ to $48^{\circ} 57^{\prime} 52^{\prime \prime}$ eastern longitude and from $33^{\circ} 16^{\prime} 21^{\prime \prime}$ to $33^{\circ} 23^{\prime} 00^{\prime \prime}$ northern latitude. Maximum elevation at sea level is 3287 meter and the minimum in outlet of watershed is 2121 meter. Figure 1 shows the position of the watershed in Iran and Lorestan province.

\subsection{Green-Ampt (G-A) Infiltration Model}

Green-Ampt (G-A) model [12] is one of the conceptual models which has been edited based on Darsi and the concept of the incorporation of its equations. The basis of this model is simple and its parameters can be easily calculated with using the physical properties of soil [13]. In this model the velocity of infiltration and the cumulative infiltration rate is calculated as following Equations (1)-(4):

$$
f(t)=k\left(1+\frac{\psi \cdot \Delta \theta}{F(t)}\right)
$$




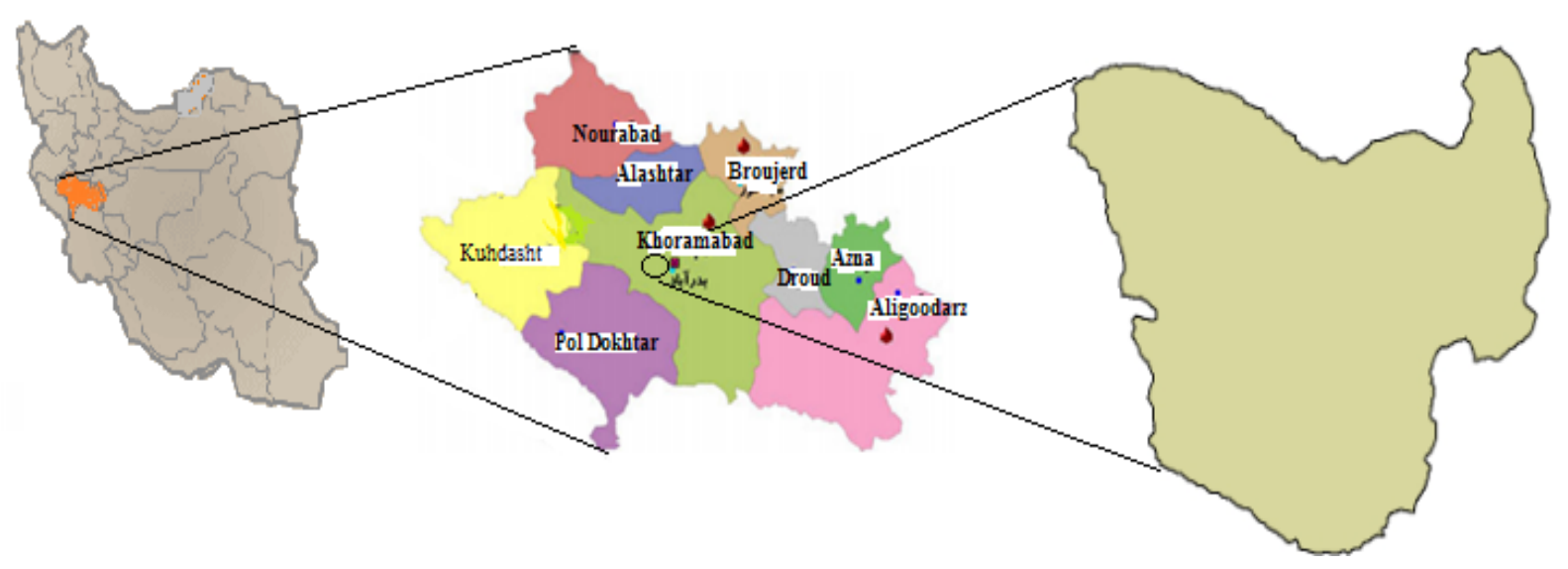

Figure 1. Geographical position of the Kakasharaf watershed in Iran and Lorestan.

$$
\begin{array}{r}
f(t)=k\left(\cos \theta+\frac{\psi \cdot \Delta \theta}{F(t)}\right) \\
f(t)=k(\cos \theta)+k \frac{\psi \cdot \Delta \theta}{F(t)} \\
\Delta \theta=\eta-\theta t
\end{array}
$$

where $F(t)$ is the infiltration rate in $\mathrm{cm}$ per hour, $K$ is the hydraulic conductivity in $\mathrm{cm}$ per hour, $\psi$ is water absorption in moist area in $\mathrm{cm}, \Delta \theta$ is the difference of primary moisture percentage and the porosity degree, $F(t)$ is the cumulative infiltration rate in $\mathrm{cm}, T$ is the time of rainfall beginning in hour, $\eta$ is porosity rate, $\theta t$ is the primary moisture percentage and $\theta$ is slope gradient.

\subsection{Artificial Neural Network}

In a previous decade the hydrologists have severely focused on artificial neural network which some of them areascale [14] [15] and others. All of these researchers proved the power of this method in modeling of different phenomena especially non-linear phenomena. The rainfall-runoff follows a non-linear model. So, in this research multi-layer Prespetron artificial neural network (MLP) which is a type of feed forward Neural Network was used beside the sigmoid conversion function (S).

\subsection{WMS Model}

Modeling system of watershed (WMS) is a comprehensive modeling environment for all hydrological and hydraulic phases of watershed. This software includes powerful tools for auto-modeling of process such as Autoextraction of watershed, calculation of geometrical parameters, calculation of layers overlap in GIS (CN, runoff depth, rugged coefficient and etc), extraction of cross section of terrain data and other properties in WMS. Accessibility to this aim is not possible if the proper methods are used. General stages of this research have been illustrated in Figure 2.

\subsubsection{Collection of Data and Necessary Spatial Data}

- Daily precipitation, evaporation and discharge in 10-year statistical period from 2001-2010

- Maps: basic topography map, thematic maps (land use and soil texture)

- Satellite image of region in different times

- Measured infiltration rate in region using empirical method of multiple rings (Double rings) to evaluate and validate infiltration rate.

Kakasharaf-Chenarsokhteh (Khoshkeh) station is located at the outlet of watershed. This station was considered as indicator station and its discharges data was used as outlet discharge. The data of all stations in wa- 


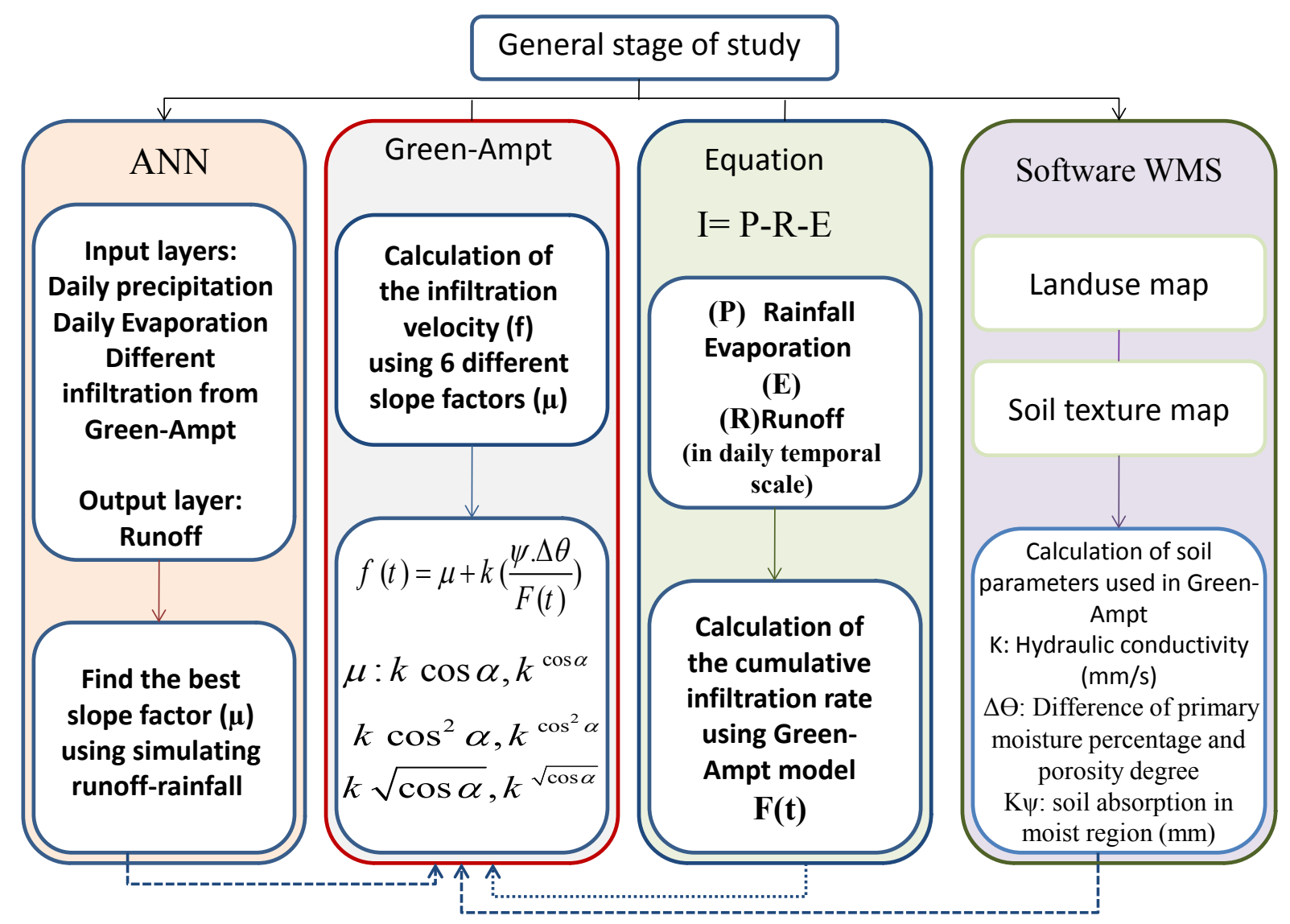

Figure 2. General stages of research.

tershed is required to estimate mean rainfall of watershed using polygon Thissen method. In this research the rainfall data of Khorram Abad station, ChamAnjir and Dehnou was used.

\subsubsection{Data Preparation and Data Correction}

- Selection of common statistical period

- Rebuilding data defects

- Data homogenous test

- Interpolationprecipitation data (Polygon Thissen)

- Calculation of effective area for each station

\subsubsection{Calculation of the Cumulative Infiltration Rate F(t) Used in Green-Ampt Model}

Balanced equation was used to calculate the parameter of cumulative infiltration. Daily rainfall, evaporation and runoff were used in this method. The measured runoff at the watershed outlet is the total rate of runoff. So, the basic discharge rate was separated from total runoff to achieve direct runoff in balance equation. In this research feedback numerical filtering with filter coefficient 0.925 was used.

\subsubsection{Calculation of the Soil Parameters Used in Empirical Model of Green-Ampt}

After the conversion of the format of thematic maps and conversion of soil texture map to hydrological groups map, the infiltration coefficients of Green-Ampt model $(\Delta \theta, \psi, K)$ were estimated using land use and soil texture maps in WMS 7.1 software as following:

$K$ is the hydraulic conductivity in $\mathrm{cm}$ per hour

$\psi$ is water absorption in moist area in $\mathrm{cm}$

$\Delta \theta$ is the difference of primary moisture percentage and the porosity degree 
In Green-Ampt model the geographical information system was used to prepare slope map of Kakasharaf watershed and calculating the average slope of watershed.

\subsubsection{Determining the Best Slope Factor $(\mu)$ in Green-Ampt Model}

By using artificial neural network (ANN), Different slope factors have been defined for the infiltration model of Green-Ampt which differs for each area based on its condition. These factors are as following:

$$
\mu=\cos \alpha, \mu=\sqrt{\cos \alpha}, \mu=1 / \cos \alpha, \mu=1 / \cos ^{2} \alpha, \mu=1 / \sqrt{\cos \alpha}, \mu=\cos ^{2} \alpha
$$

where $\mathrm{S}$ is the slope gradient and $\mu$ is the slope factor. The input of ANN model were rainfall, evaporation, evapotran spiration and infiltration rate of previous stage which all of these factors are in daily temporal scale. Programming language of MATLAB 7.8 software was used for modelling of runoff-rainfall.

Finally the best slope factor is the value which the runoff-rainfall modelling had minimum error rate and maximum performance. The real runoff and simulated runoff was compared together using statistical indices of correlation coefficient, performance coefficient of Nash-Sutcliff, mean square error, root of mean square error and the performance model of bias. The equation of these criteria is as following Equations (5)-(8):

Mean of square error

$$
\mathrm{MSE}=\sum_{i=1}^{n}\left(\frac{Q_{o_{i}}-Q_{s_{i}}}{n}\right)
$$

2) Root of mean square error

$$
\mathrm{RMSE}=\sqrt{\sum_{i=1}^{n}\left(\frac{Q_{o_{i}}-Q_{s_{i}}}{n}\right)}
$$

3) Performance model of Nash-Sutcliff

$$
\text { Nash }=1-\frac{\sum_{i=1}^{n}\left(Q_{s_{i}}-Q_{o_{i}}\right)^{2}}{\sum_{i=1}^{n}\left(Q_{o_{i}}-\bar{Q}_{o_{i}}\right)}
$$

4) Performance model of Bias

$$
\mathrm{MB}=\frac{\sum_{i=1}^{n}\left(Q_{s_{i}}-Q_{o_{i}}\right)}{\sum_{i=1}^{n} Q_{o_{i}}}
$$

where in all of these equations $Q_{s_{i}}$ is simulated runoff rate $Q_{o_{i}}$ is the measured runoff rate (observation) and $\mathrm{n}$ is the data number. There is the best correlation between the observation data and simulated data if the performance coefficient of Nash-Sutcliff and coefficient of determination is near to one and the mean square error, root of mean square error and the performance model of bias is near to zero.

\subsubsection{Comparison between the Observed Data and Estimated Data}

In this research the infiltration capacity was separately measured for different land use in three replications. Totally 27 sample were taken. The average of measured infiltration rate in different times was calculated for each landuse and then the capacity of water infiltration was achieved for each landuse using Kostiakov model. The general infiltration rate of watershed was calculated using weighted average and the estimated infiltration was calculated and compared using the integrating of ANN and WMS, Green-Ampt model, measured infiltration in region by double ring. The data of double ring were compared to estimated data in temporal, temperature, evaporation and soil moisture aspects.

\section{Results}

In this research a 10-year statistical period from 2001-2002 to 2010-2011 was selected as indicator period. The selected period was new, so the statistics had no defects and it is not required to rebuilding. Results of the homogenous test by duplicated weight showed that the data of all three stations of Khoram Abad, Chamanjir and 
Dehnou were homogenous. Results of the interpolating rainfall data showed that the effects of each rainfall stations are as following (Table 1 ):

Then with inserting the maps of soil texture and land use in MWS 7.1 the infiltration coefficient of Green-Ampt model $(\Delta \theta, \psi, K)$ was estimated which this coefficient has been shown in Table 2.

After the preparation of the slope map of Kakasharaf watershed (Figure 3), the mean weighted slope of watershed was calculated which was equal to $26.4 \%$ ? According to the geometrical equations this gradient is equal to 14.8 degree.

For determining the best slope factor using runoff-rainfall modeling it is required to model different infiltration of various slope factors separately. Finally the best slope factor is the value which has the minimum error and maximum performance coefficient based on runoff-rainfall model. The results of the calculation of best slope factor $(\mu)$ in Green-Ampt model using artificial neural network (ANN) has been shown in Table 3.

The slope factor of $K \sqrt{\cos \alpha}$ with most coefficient of determination $\left(R^{2}\right)$ and performance coefficient of

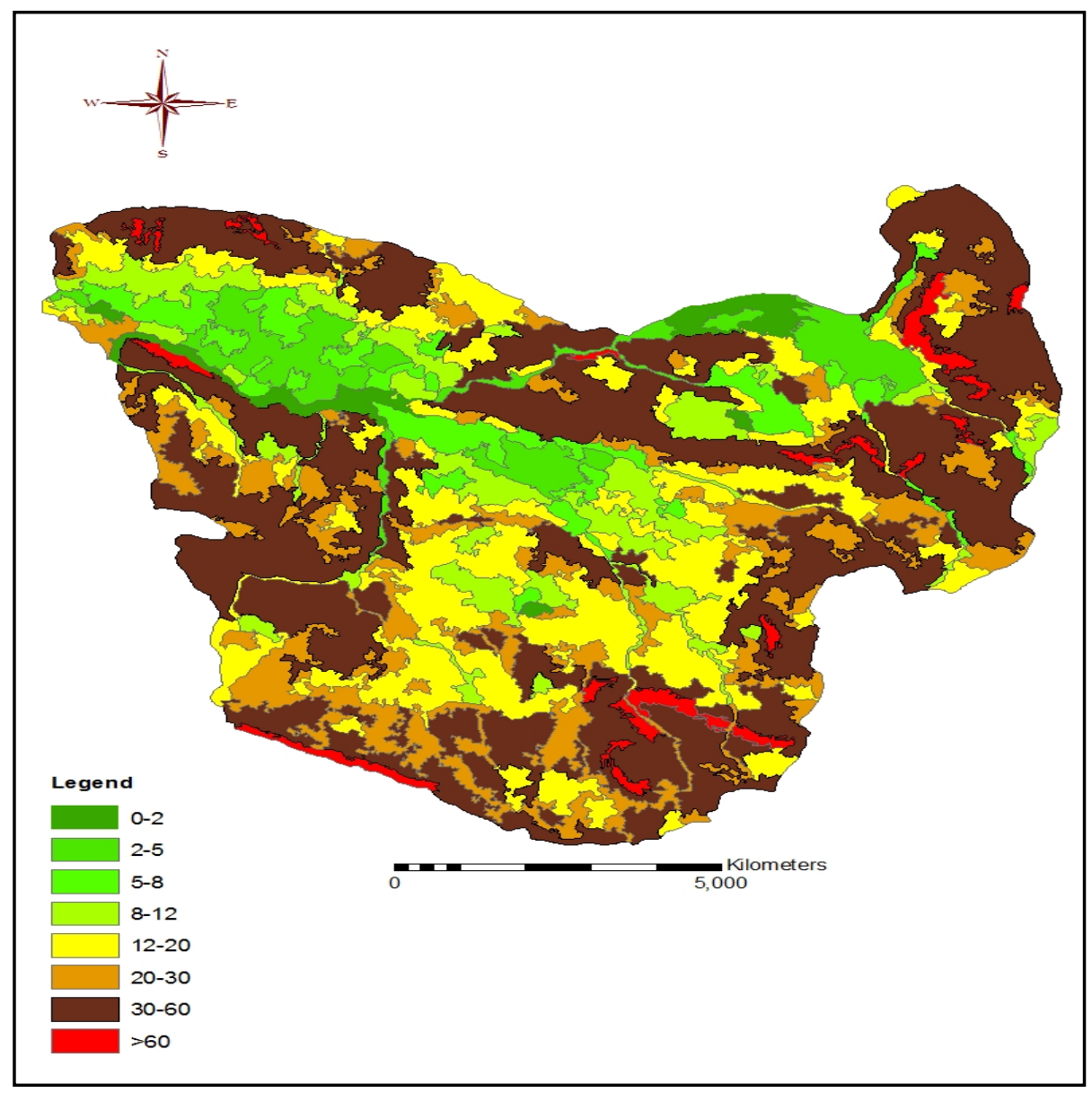

Figure 3. The map of slope in Kakasharaf watershed.

Table 1. The values of the level of effects of rainfall stations around Kakasharaf watershed after designing Thissen polygon.

\begin{tabular}{ccc}
\hline Station & Area $\left(\mathrm{km}^{2}\right)$ & Level of station effect $(\%)$ \\
\hline Harroud Dehnou & 52.84 & 48.9 \\
Khoram Abad & 50.44 & 46.71 \\
Cham Anjir & 4.69 & 0.04 \\
Total & 107.97 & 100 \\
\hline
\end{tabular}


Table 2. Physical parameters estimated from WMS model.

\begin{tabular}{|c|c|c|c|c|}
\hline Row & Physical parameters of soil & Values & $\begin{array}{l}\text { Coefficient unit in model } \\
\text { WMS }\end{array}$ & $\begin{array}{l}\text { Coefficient unit in } \\
\text { Green-Ampt model }\end{array}$ \\
\hline 1 & $K$ is the hydraulic conductivity in $\mathrm{cm}$ per hour & 0.00253 & $\mathrm{~mm} / \mathrm{s}$ & $\mathrm{Cm} / \mathrm{h}$ \\
\hline 2 & $\psi$ is water absorption in moist area in $\mathrm{cm}$ & 1.6 & $\mathrm{Mm}$ & $\mathrm{cm}$ \\
\hline 3 & $\begin{array}{l}\Delta \theta \text { is the difference of primary moisture } \\
\text { percentage and the porosity degree }\end{array}$ & 2.3 & $\%$ & $\%$ \\
\hline
\end{tabular}

Table 3. Results of the comparison of observed and simulated runoff.

\begin{tabular}{|c|c|c|c|c|c|}
\hline $\mathrm{MB}$ & RMSE & NASH & MSE & $R^{2}$ & Slope factor \\
\hline 0.121 & 0.063 & 0.940 & 0.004 & 0.798 & $K \cos \alpha$ \\
\hline-0.164 & 0.170 & 0.560 & 0.029 & 0.655 & $K^{\cos \alpha}$ \\
\hline 0.240 & 0.089 & 0.877 & 0.008 & 0.730 & $K \cos ^{2} \alpha$ \\
\hline 0.127 & 0.104 & 0.823 & 0.011 & 0.776 & $K^{\cos ^{2} \alpha}$ \\
\hline 0.117 & 0.028 & 0.988 & 0.0008 & 0.915 & $K \sqrt{\cos \alpha}$ \\
\hline-0.215 & 0.094 & 0.856 & 0.009 & 0.751 & $K^{\sqrt{\cos \alpha}}$ \\
\hline
\end{tabular}

Nash-Sutcliff and minimum values of mean square error (MSE) and root of mean square error (RMSE) as well as bias performance model (MB) was selected as the best slope factor in conceptual infiltration model of Green-Ampt for study watershed. Finally, the estimated infiltration rate with integrating models of ANN and WMS as well as Green-Ampt infiltration model was evaluated and compared with double ring measured infiltration rate in region using indices of correlation coefficient, mean square error, root of mean square error, performance coefficient of Nash-Sutcliff and bias performance model which results has been shown in Table 4.

\section{Discussion and Conclusion}

Most of the models of infiltration estimation considered zero for the slope factor, whereas this factor has a very important role in infiltration process. The conceptual and physical model (modified Green and Ampt model) is one of a few infiltration models that considers slope as an input parameter in its formulationas Richards infiltration equation. 6 different slope factors were defined for this model, thus one of them must be selected as the best factor which performs in artificial neural network (ANN) and runoff-rainfall process. Artificial neural network shows the high capability in simulating runoff-rainfall which was in agreement with the finding of references [16] [17].

Results of the selection of best slope factor showed that factor $K \sqrt{\cos \alpha}$ with highest Nash-Sutcliff coefficient and lowest model error (MB) was selected as the best slope factor in study area which was not in agreement with the findings of the past research which introduced the $K \cos ^{2} \alpha$ as the best slope factor for the Johoor watershed in south of Malaysia. Many factors such as climate, topography, soil texture, etc can affect infiltration and slope factors changes according to study area. Beside the slope factors, other factors such as soil texture and landuse type can be effective on the infiltration of the area. In recent research the Green-Ampt parameters $(K, \psi, \Delta \theta)$ can be computed by overlaying Land use and soil type map in WMS7.1 environment. Thus, other three coefficients of Green-Ampt model were weighted according to soil texture and landuse type which was done according to physical properties of study area therefore was in agreement with the real status. Finally, the estimated infiltration rate of Green-Ampt model was compared to the measured infiltration values by double ring method.

According to the sensitivity of the issue of soil infiltration, this comparison need similar conditions in climate and soil properties. Therefore the measure data were compared to estimated infiltration rates in similar temperature, evapotranspiration, previous soil moisture and time (similar months and days). Comparison of the results of estimated infiltration using corrected Green-Ampt model and the measured infiltration by double rings showedthat the Green-Ampt model had high capability to estimate infiltration of study area which was in agreement 
Table 4. Results of the comparison of the estimated infiltration and observed infiltration by double ring.

\begin{tabular}{cccccc}
\hline MB & RMSE & NASH & MSE & $R^{2}$ & Statistical index \\
\cline { 2 - 5 } 0.024 & 0.216 & 0.821 & 0.047 & 0.905 & Value \\
\hline
\end{tabular}

with the findings of references [18] [19].

\section{References}

[1] Skandarinia, A., ZiatabarAhmadi, M., Nazarpour, H., Teimori, M. and Moshfegh, M.Z. (2005) Investigation of the Effects of Previous Rainfall Factor in Estimating of Stream Flow Using the Modeling of Rainfall-Runoff. Eight International Congress of Civil Engineering, Shiraz University, 12 May 2005.

[2] El-shafie, A., Mukhlisin, M., Najah, A.A. and Taha, M.R. (2011) Performance of Artificial Neural Network and Regression Techniques for Rainfall-Runoff Prediction. International Journal of Physical Sciences, 6, 1997-2003.

[3] Braud, I., De Condappa, D. and Soria, J.M., Haverkamp, R., Angulo-Jaramillo, R., Galle, S. and Vauclin, M. (2005) Use of Scaled Forms of the Infiltration Equation for the Estimation of Unsaturated Soil Hydraulic Properties (the Beerkan Method). European Journal of Soil Science, 56, 361-374. http://dx.doi.org/10.1111/j.1365-2389.2004.00660.x

[4] Mohammadi, M.H. and Refahi, G.H. (2005) Estimation of the Equation Parameters of Infiltration Using Physical Properties of Soil. Journal of Agricultural Science, 36, 1398-1391.

[5] Fernández-Gálvez, J., Barahona, E. and Mingorance, M. (2008) Measurement of Infiltration in Small Field Plots by a Portable Rainfall Simulator Application to Trace-Element Mobility. Water, Air, Soil Pollute, 191, 257-264. http://dx.doi.org/10.1007/s11270-008-9622-2

[6] Vaghefi, M. (2004) Definition of the Conceptual Infiltration Model and Converting Crude Rainfall to Pure Rainfall in Southern Watersheds of Country. First National Conference of Civil Engineering, 22-23 May 2004.

[7] Chu, S.T. (1978) Infiltration during Unsteady Rain. Water Resources Research, 14, 461-466. http://dx.doi.org/10.1029/WR014i003p00461

[8] Chu, S.T. (1985) Modeling Infiltration on Tilled Soil during Non-Uniform Rain. Transaction of the ASAE 28, 4, 12261232. http://dx.doi.org/10.1029/WR014i003p00461

[9] Hsu, S.M., NI, C.F. and Hung, P.F. (2002) Assessment of Three Infiltration Formulas Based on Model Fitting and Richards Equation. Journal of Hydrology, 7, 373-379. http://dx.doi.org/10.1061/(ASCE)1084-0699(2002)7:5(373)

[10] Ma, Y., Feng, S., Su, D., Gao, G. and Huo, Z. (2009) Modeling Water Infiltration in a Large Layered Soil Column with a Modified Green-Ampt Model and HYDRUS-1 D. Computers in Agriculture.

[11] Dorofki, M., Elshafie, A.H., Jaafar, O., Karim, O.A. and Abdullah, S.M.S. (2011) A GIS-Based Survey for the Optimization of Infiltration Forecasting Models with Emphasis on Slope Effect and Land Use. International Journal of the Physical Sciences, 6, 5738-5751.

[12] Green, W.H. and Ampt, C.A. (1911) Studies on Soil Physics, I. Flow of Water and Air through Soils. Journal of Agricultural Science, 4, 1-24.

[13] Brakensiek, D.L. and Onstad, C.A. (1977) Parameter Estimation of the Green and Ampt Infiltration Equation. Water Resources Research, 13, 1009-1012. http://dx.doi.org/10.1029/WR013i006p01009

[14] Smith, J. and Eli, R.B. (1955) Neural Network Models of Rainfall-Runoff Process. Journal of Water Resources Planning and Management, 4, 232-239.

[15] Sabol, G., Rumann, J., Khalili, D., Waters, S. and Lehman, T. (1995) Rainfall Losses in Drainage Design Manual for Maricopa County, Arizona, Vol. 1: Hydrology. Flood Control District of Maricopa County, Arizona, 1-19.

[16] Akbarpour, M., Rahnama, B. and Barani, G.H. (2003) Comparison of the Artificial Neural Network and HEC-HMS Model in Rainfall Process. 4th Hydraulic Conferences of Iran, Shiraz, September 2003.

[17] Tokar, A.S. and Markus, M. (2000) Precipitation-Runoff Modeling Using Artificial Neural Networks and Conceptual Models. Journal of Hydrologic Engineering, 5, 156-161. http://dx.doi.org/10.1061/(ASCE)1084-0699(2000)5:2(156)

[18] Smemoe, C.M., Nelson, E.J. and Zhao, B. (2004) Spatial Averaging of Land Use and Soil Properties to Develop the Physically-Based Green and Ampt Parameters for HEC-1. Environmental Modelling \& Software, 19, 525-535. http://dx.doi.org/10.1016/j.envsoft.2003.07.001

[19] Mousavi, S.A., Asadi, H., Norouzi, M. and Ghavidel far, S. (2010) Investigation of the Green-Ampt Model in Navroud Indicator Watershed Using Field Survey and Infiltration Measurement with Double Rings. Research Findings of Water Company of Guilan Province. 